\title{
Sporulation of Aspergillus niger and Aspergillus ochraceus in Continuous Submerged Liquid Culture
}

\author{
By A. J. BRODERICK AND R. N. GREENSHIELDS* \\ Fermentation Laboratory, Department of Biological Sciences, University of Aston in \\ Birmingham, Gosta Green, Birmingham B4 7ET, U.K.
}

(Received 13 November 1980; revised 27 February 1981)

\begin{abstract}
Sporulation of Aspergillus niger and Aspergillus ochraceus was induced in a continuous tower fermenter by restricting growth by nutrient limitation. Shock carbon limitation produced no sporulation, but the gradual decrease of sucrose or starch supply to $A$. niger produced slight sporulation. Gradual nitrate limitation produced no sporulation, while a shock decrease in nitrate concentration caused heavy sporulation of both organisms. The previously unobserved morphology of the sporulating structures produced was much simplified under nitrate limitation, but similar to sub-aerial morphology under carbon limitation. Maintenance energy values for sucrose and starch were calculated for $\boldsymbol{A}$. niger and for starch for $A$. ochraceus. The continuous tower fermenter system was found to be ideal for controlling organism morphology and thus sporulation.
\end{abstract}

\section{INTRODUCTION}

Suppression of submerged conidiation of filamentous fungi has been described as a feature characteristic of shake cultures (Cochrane, 1958). Several studies since have examined the induction of submerged sporulation by manipulation of cultural conditions (Smith et al., 1977). Conidiation is considered to be a response to environmental conditions which severely restrict vegetative growth. Vezina et al. (1965) achieved conidiation of several filamentous fungi, including Aspergillus ochraceus, in submerged culture, and emphasized the importance of equilibrium between medium composition and physicochemical conditions. Sporulation may be induced by exhaustion of the carbohydrate source while nitrogen is in excess [Galbraith \& Smith (1969a), for A. niger], or by exhaustion of available nitrogen in the presence of assimilable carbohydrate [Morton et al. (1960) and Morton (1961), for Penicillium griseofulvum; Hadley \& Harrold (1958), for P. notatum; Carter \& Bull (1969), for Aspergillus nidulans; Weiss \& Turian (1966), for Neurospora crassa]. Galbraith \& Smith (1969 a) concluded that conidiation of $A$. niger depended upon the type and concentration of the nitrogen source. Batch cultivation consists of transient environments, while chemostat culture allows steady-state selective enhancement of specific morphological life cycle stages. $\mathrm{Ng}$ et al. (1973) described the conidiation of $A$. niger in continuous culture under citrate and nitrogen limitation, which showed that growth and sporulation are not necessarily mutually exclusive. Righelato et al. (1968) and Hsu \& Ordal (1969) have also studied sporulation of fungi in chemostat culture; their results indicate that both the nature and concentration balance of the medium are important. The aim of this study was to develop a commercial fermentation system for the continuous production of conidia of $A$. niger and A. ochraceus using the continuous tower fermenter, and to study the sporulation morphologies induced.

\section{METHODS}

Organisms. Master cultures of Aspergillus niger Van Tieghem (no. 38 of the fermentation laboratory culture collection; ex Dr Drysdale, Department of Genetics, Birmingham University) and Aspergillus ochraceus Wilhelm 
(CMI 16247iv) were maintained on malt-extract agar slopes at $4{ }^{\circ} \mathrm{C}$ and subcultured every 6 months. The suitability of $A$. niger for work in the continuous tower fermenter system has previously been confirmed, and $A$. ochraceus was used because of its similarity to $A$. niger and because the importance of the spores in pharmaceutical reactions has been reported (Dulaney et al., 1955; Schleg \& Knight, 1962; Sehgal et al., 1968; Haines \& Collingworth, 1953).

Fermentation equipment. Fermentations were conducted at $30^{\circ} \mathrm{C}$ in one of two glass tubular fermenter vessels, one of 101 working volume, the other of 4.21 . The design, construction and applications of the tower fermenter are described by Greenshields \& Smith (1971, 1974), Smith \& Greenshields (1974) and Cocker \& Greenshields (1975). The basic 101 design consists of three $40 \mathrm{~cm}$ lengths of standard $10 \mathrm{~cm}$ internal diameter Pyrex glass pipework, joined by polytetrafluoroethylene (PTFE) gaskets and clamped water tight. Spent medium and gases pass out of the top of the vessel via an $8 \mathrm{~mm}$ internal diameter glass swan-neck, and sterile compressed air (supplied to each fermenter at 1 vol. vol. ${ }^{-1} \mathrm{~min}^{-1}$ ) enters at the base and is dispersed before passing upwards by a PTFE air distributor plate. The 4.21 fermenter has an identical aspect ratio to the 101 fermenter $(90.0 \times 7.5 \mathrm{~cm})$ but the main body of the fermenter is in one piece. Both vessels have facilities for continuous monitoring and control of $\mathrm{pH}$, temperature and dissolved oxygen.

Preparation of inocula. A malt-extract agar mat was prepared in the base of a $250 \mathrm{ml}$ conical flask, inoculated with the appropriate mould from the sub-master culture and incubated at $30-35^{\circ} \mathrm{C}$ for 3 weeks. After this time, a full spore mat had formed, and the spores were removed by addition of $100 \mathrm{ml}$ of a $0.1 \%(\mathrm{v} / \mathrm{v})$ sterile solution of Tween 80 wetting agent, followed by vigorous agitation. The resulting spore suspension was aseptically injected into the fermenter.

Media. The basal medium constituents were $\left(\mathrm{g}^{-1}\right)$ : sucrose, $5.0 ;\left(\mathrm{NH}_{4}\right)_{2} \mathrm{SO}_{4}, 1.0 ; \mathrm{NaH}_{2} \mathrm{PO}_{4} . \mathrm{H}_{2} \mathrm{O}, 0.5 ; \mathrm{KCl}$, $0.25 ; \mathrm{MgSO}_{4} .7 \mathrm{H}_{2} \mathrm{O}, 0.1 ; \mathrm{CaCl}_{2}, 0.05$; yeast extract, 0.5 . Sucrose was replaced in some experiments by glucose or starch equivalent. $\left(\mathrm{NH}_{4}\right)_{2} \mathrm{SO}_{4}$ was sometimes replaced by $\mathrm{NaNO}_{3}\left(1.3 \mathrm{~g} \mathrm{l}^{-1}\right)$. Media were sterilized by autoclaving in 201 batches at $121^{\circ} \mathrm{C}$ for $20 \mathrm{~min}$.

Methods of nutrient limitation. Limiting levels selected were based upon the principle of decreasing nutrient supply until equal to or below the maintenance requirements of the organism. The criteria for nitrogen limitation were determined in two ways: firstly, by lowering the nitrogen content of the medium to below the level of utilization at maximum growth rate under optimum conditions at a steady state, while maintaining all other parameters optimal; secondly, by decreasing the nitrogen level to that used by other workers to induce sporulation in batch culture. Galbraith \& Smith $(1969 a)$ stated that conidium formation is inhibited by the presence of nitrate at concentrations at or above $60 \mathrm{mg} \mathrm{N}{ }^{-1}$ and conidiophores are inhibited by concentrations at or above $120 \mathrm{mg}$ $\mathrm{N}^{-1}$. In our experiments the nitrogen content of the medium was therefore decreased to $20 \mathrm{mg} \mathrm{N}^{-1}$, and at times to zero [Anderson \& Smith (1971a) used a nitrogen-free medium to induce conidiophore elongation]. To provide gradual nitrogen limitation, stepwise reductions in the nitrogen content of the medium were made between the establishment of each steady state. Shock treatment was introduced by removing the medium supplying the optimum nitrogen supply $\left(0.21 \mathrm{~g} \mathrm{~N}^{-1}\right)$ and replacing this immediately with one containing approximately $0.02 \mathrm{~g}$ $\mathrm{N}^{-1}$, without altering any other environmental parameter. The effect upon growth of the organism was then monitored. The principles of carbon limitation (gradual and shock) were identical to those of nitrogen limitation, except that a concomitant decrease in dilution rate with carbon level was examined for both shock and gradual limitation. Details of each limitation are given in Results.

Dilution rate. The majority of experiments were conducted at dilution rates of $0.2 \mathrm{~h}^{-1}$ or $0.1 \mathrm{~h}^{-1}$, although lower rates were used during carbon-limited fermentations.

Analytical methods. Total sugar concentration of medium and effluent was determined by the method of Dubois et al. (1956), with reference to a standard curve constructed for each kind of carbohydrate supply (expressed as $\mathrm{g}$ sugar ${ }^{-1}$ ). Nitrate and nitrite content of medium and effluent (expressed as $\mathrm{g} \mathrm{N}^{-1}$ ) were determined by the method

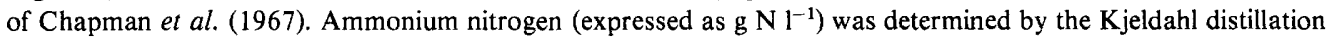
method of Markham (1942).

Fermenter sampling. Samples of $100 \mathrm{ml}$ were collected from $(a)$ the effluent stream and $(b)$ the tower, and filtered through fine muslin; the mycelial dry weight $\left(\mathrm{g} \mathrm{l}^{-1}\right)$ was determined by drying the residual biomass at $105^{\circ} \mathrm{C}$ for $24 \mathrm{~h}$. These measurements gave $(a)$ the effluent biomass concentration $\left(x_{\mathbf{E}}\right)$, and $(b)$ the fermenter biomass concentration $\left(x_{\mathrm{F}}\right)$.

Microscopy. The production of sporulation structures was assessed by direct observation of fresh mycelial samples. Spore numbers were recorded by counting free conidia in an effluent sample after vigorous agitation, using an Improved Neubauer counting chamber.

Fermentation parameters. Dilution rate $(D)$ was calculated by $f / V$, where $f$ is the flow rate of medium supply $(1$ $\mathrm{h}^{-1}$ ) and $V$ is the volume of the fermenter (l). The specific growth rate $(\mu)$ during a steady state was then calculated from the equation $\mu=D x_{\mathrm{E}} / x_{\mathrm{F}}$. The factor $D x_{\mathrm{E}}$ represents the productivity $(Y)$ of the system $\left(\mathrm{g}^{-1} \mathrm{~h}^{-1}\right)$. Growth rate in transient states was calculated by the equation

$$
\mu=\left(1 / x_{\mathrm{Ftotal}}\right) \times(\text { New biomass produced } / \Delta t)
$$


where

$$
x_{\mathrm{Ftotal}}=V\left(x_{\mathrm{F} 1}+x_{\mathrm{F} 2}\right) / 2
$$

New biomass produced $=f \bar{x}_{\mathrm{E}} \Delta t+V\left(x_{\mathrm{F} 2}-x_{\mathrm{F} 1}\right)$

$\Delta t$ is the time elapsed between time 0 and time $t, x_{\mathrm{F} 1}$ and $x_{\mathrm{F} 2}$ are the fermenter biomass concentrations at time 0 and time $t$, respectively, and $\bar{x}_{\mathrm{E}}$ is the mean effluent biomass concentration between time 0 and time $t$. Where dilution rate varied during an experiment, the substrate supply rates $\left(K_{\mathrm{s}}\right.$ for sugar, $K_{\mathrm{N}}$ for nitrogen; $\left.\mathrm{g} \mathrm{h}^{-1}\right)$ were calculated by $K_{\mathrm{s}}=s_{\mathrm{m}} f$ and $K_{\mathrm{N}}=N_{\mathrm{m}} f$, where $s_{\mathrm{m}}$ and $N_{\mathrm{m}}$ are the concentrations of sugar and nitrogen in the medium, respectively. The maintenance coefficient $\left(m ; \mathrm{g} \mathrm{g}^{-1} \mathrm{~h}^{-1}\right)$, representing the quantity of substrate consumed by cells for functions other than growth, was calculated by the method of Schulze \& Lipe (1964), using regression analysis. The specific substrate utilization rate for sugar $\left(q_{\mathrm{s}} ; \mathrm{g} \mathrm{g}^{-1} \mathrm{~h}^{-1}\right)$, was calculated by the equation $q_{\mathrm{s}}=$ $\Delta s D / x_{\mathrm{F}}$, where $\Delta s$ is sugar utilization $\left(\mathrm{g}^{-1}\right)$. To express the intensity of sporulation, a sporulation index $(\beta)$ was used (Hadley \& Harrold, 1958) which represents the number of spores per $\mathrm{g}$ dry wt mycelium.

Replication. Where no time scale appears on the graphs, a result represents the mean of steady-state values recorded over at least $3 \mathrm{~d}$. Mean nutrient levels were calculated from at least three analytical replicates, and mean growth rate and productivity values were obtained from triplicate $x_{\mathrm{E}}$ and $x_{\mathrm{F}}$ sample analyses. Where a time scale monitors a transient state, a point represents the mean value of the means of two or three replicates of the experiment.

\section{RES ULT S}

Several authors have expressed the opinion that ammonium ions are either inhibitory or detrimental to sporulation (Galbraith \& Smith, 1969a). The $\left(\mathrm{NH}_{4}\right)_{2} \mathrm{SO}_{4}$ of the basal medium was therefore replaced by $\mathrm{NaNO}_{3}$. This had no adverse effect upon the optimum growth rates of either organism at a dilution rate of $0.1 \mathrm{~h}^{-1}$ in continuous culture. The mean growth rates of $A$. niger and $A$. ochraceus in $\left(\mathrm{NH}_{4}\right)_{2} \mathrm{SO}_{4}$ medium were $0.062 \mathrm{~h}^{-1}$ and $0.051 \mathrm{~h}^{-1}$, respectively, while in $\mathrm{NaNO}_{3}$ medium the respective growth rates were $0.06 \mathrm{~h}^{-1}$ and $0.05 \mathrm{~h}^{-1}$. Thus the growth rate of $A$. ochraceus is lower than that of $A$. niger in this system.

\section{Carbon limitation}

Shock limitation. Several fermentations were performed using sucrose as the carbon source at $D=0.2 \mathrm{~h}^{-1}$; after achieving steady state (on $5 \mathrm{~g} \mathrm{l}^{-1}$ sucrose plus normal basal medium) the sucrose concentration of the medium $\left(s_{\mathrm{m}}\right)$ was lowered to $0.25 \mathrm{~g}^{-1}$, i.e. $K_{\mathrm{s}}$ decreased from 4.2 to $0.21 \mathrm{~g} \mathrm{~h}^{-1}$ (Fig. 1). In this case limitation was imposed on day 8 , but the limitation was too severe at this dilution rate, and washout occurred within $3 \mathrm{~d}$, with no sign of sporulation. The peaks of productivity $(Y)$ and growth rate $(\mu)$ the day after limitation was imposed are false values due to the high $x_{\mathbf{E}}$ values resulting from washout.

These experiments were repeated imposing a similar shock carbon limitation $\left(K_{\mathrm{s}}\right.$ reduced from 4.2 to $0.19 \mathrm{~g} \mathrm{~h}^{-1}$ ) but with higher $s_{\mathrm{m}}$ values and lower $D$ values. Again, no sporulation resulted. Washout was more gradual but at longest the fermentation only lasted $3 \mathrm{~d}$ after initiation of sucrose limitation.

Gradual limitation. Dilution rate and sucrose concentration were gradually reduced to $A$. niger growing in otherwise optimal conditions (Fig. 2). Sporulation was achieved during this type of fermentation. In one example, sporing structures became visible in the tower contents on day $16\left(K_{\mathrm{s}} 0.4 \mathrm{~g} \mathrm{~h}^{-1}\right)$, although spores were too few to count. All the structures produced were complex sub-aerial forms with long conidiophores and large vesicles supporting many phialides, each producing spores. No spore chains were seen. Sporulation continued until the fermentation was terminated due to yeast infection. The gross morphology of the mycelium during sporulation corresponded to the type I-II form as proposed by Cocker (1980), accounting for the low $x_{\mathrm{F}}$ values encountered. A maintenance coefficient of $0.018 \mathrm{~g} \mathrm{~g}^{-1} \mathrm{~h}^{-1}$ was calculated. This experiment was repeated using A. ochraceus but the organisms washed out of the fermenter when $K_{\mathrm{s}}$ was lower than $1.0 \mathrm{~g} \mathrm{~h}^{-1}$.

Starch is a carbohydrate source which is biochemically less available to the aspergilli, due to the need for hydrolysis before utilization, and it was anticipated that starch limitation would prove more severe than sucrose limitation and thus lead to increased sporulation. The 


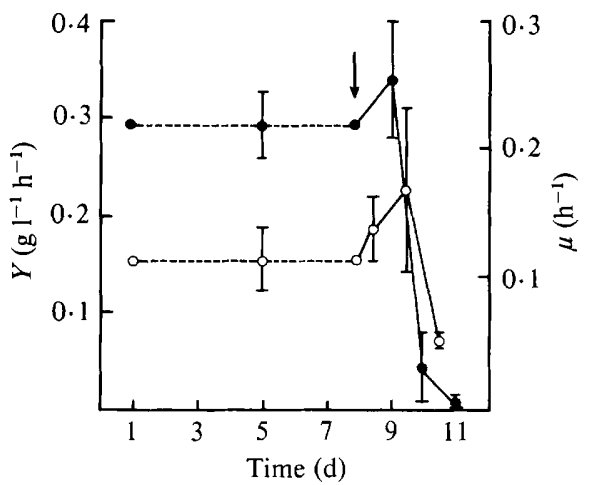

Fig. 1

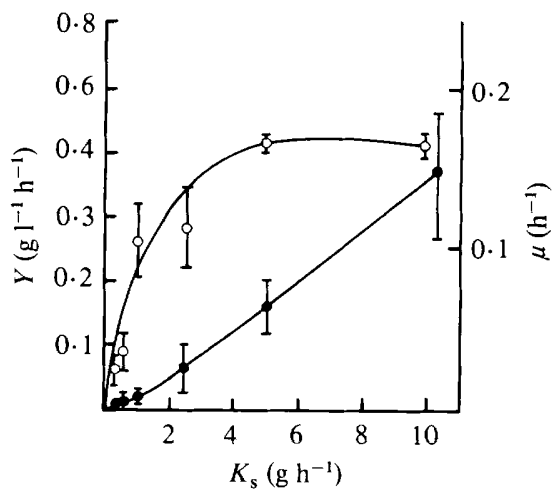

Fig. 2

Fig. 1. Effect of shock sucrose limitation [concentration in the medium suddenly decreased (arrow) from 5.0 to $0.25 \mathrm{~g}^{-1}$ ] on the growth rate, $\mu(\mathrm{O})$ and productivity, $Y(\mathrm{O})$ of $A$. niger. $D, 0.2 \mathrm{~h}^{-1} ;$ temp., $30^{\circ} \mathrm{C}$; medium $\mathrm{N}$ concentration, $0.21 \mathrm{~g} \mathrm{l}^{-1}$. The bars represent the standard error of three replicates.

Fig. 2. Combined effect of gradually decreasing the medium sucrose concentration from 5.0 to $1.0 \mathrm{~g}$ $1^{-1}$ and decreasing the dilution rate from 0.2 to $0.04 \mathrm{~h}^{-1}$ on the growth rate, $\mu(\mathrm{O})$ and productivity, $Y$ (O) of $A$. niger. (Substrate supply rate, $K_{\mathrm{s}}$, decreased from 10.0 to $0.4 \mathrm{~g} \mathrm{~h}^{-1}$.) Temp., $30^{\circ} \mathrm{C}$; medium $\mathrm{N}$ concentration, $0.21 \mathrm{~g} \mathrm{l}^{-1}$. The bars represent the standard error of three replicates.
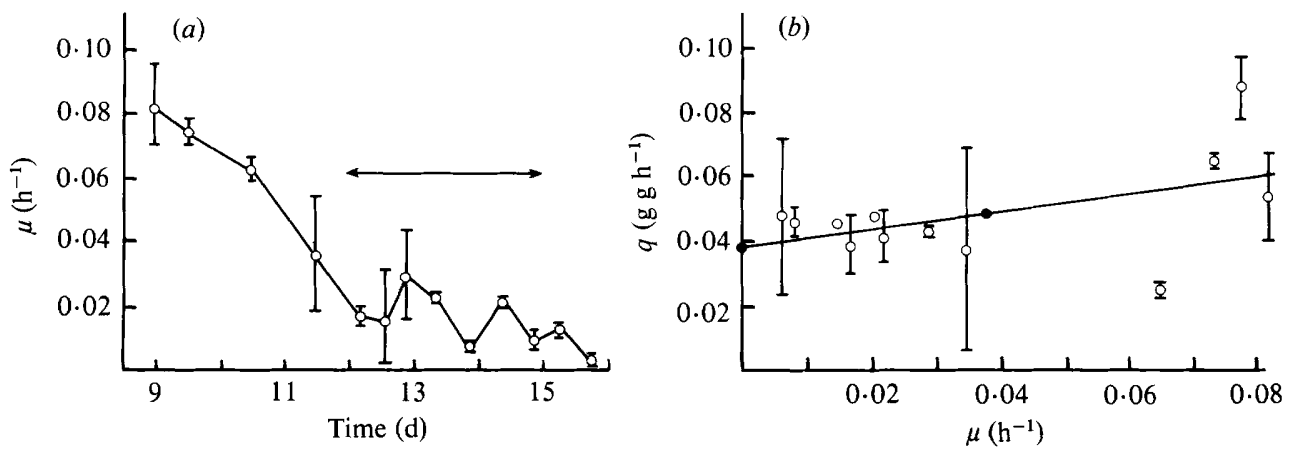

Fig. 3 (a) Gradual decrease in growth rate $(\mu)$ of $A$. niger after the imposition of a limiting starch supply of $0.6 \mathrm{~g}$ glucose equivalent $1^{-1} . D, 0.1 \mathrm{~h}^{-1}$; temp., $30^{\circ} \mathrm{C}$; medium $\mathrm{N}$ concentration, $0.21 \mathrm{~g}^{-1}$. The double-headed arrow indicates the period of sporulation. The bars represent the standard errors of three replicates.

(b) Estimation of the maintenance coefficient $(m)$ of $0.0383 \mathrm{~g} \mathrm{~g}^{-1} \mathrm{~h}^{-1}$ for starch for $A$. niger, from the data of the experiments shown in $(a)$. Specific substrate utilization rate $(q)$ is plotted against growth rate $(\mu)$. $\bigcirc$, Observed values;, regression plot. The bars represent the standard error of three replicates.

effect of the lowest starch supply to $A$. niger at $D=0 \cdot 1 \mathrm{~h}^{-1}$ is shown in Fig. 3(a). Sporulation was first noticed on day 12 ( $48 \mathrm{~h}$ after the onset of the lowest carbon feed state), when conidiophore initials were produced from foot cells. Vesicles were visible $8 \mathrm{~h}$ later, and $24 \mathrm{~h}$ later phialides and spores were present. Sporulation was not synchronous, all structures being present together, but a sporulation development time of approximately 18-24 h from vegetative mycelium to spore production was indicated. The morphology of the sporing structures was simplified, only three or four phialides being produced on each vesicle.

Sporulation was evident for $72 \mathrm{~h}$, but insufficient free spores were produced for accurate counts. At the time of sporulation the floc morphology was type I-II (Cocker, 1980). After $72 \mathrm{~h}$, sporulation ceased and the culture died. This starch limitation experiment was repeated 

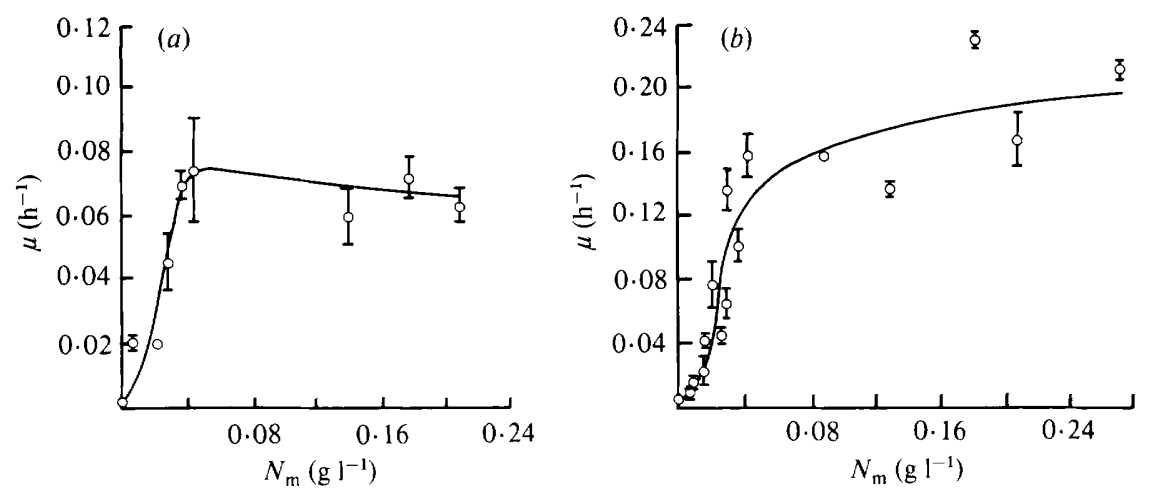

Fig. 4. Effect of gradual reduction of medium N concentration $\left(N_{\mathrm{m}}\right)$ on the growth rate $(\mu)$ of $(a) A$. ochraceus and $(b) A$. niger. $D, 0.1 \mathrm{~h}^{-1}$ in $(a)$ and $0.2 \mathrm{~h}^{-1}$ in $(b)$; temp., $30^{\circ} \mathrm{C}$; medium sucrose concentration, $5.0 \mathrm{~g} \mathrm{l}^{-1}$. The bars represent the standard errors of three replicates.
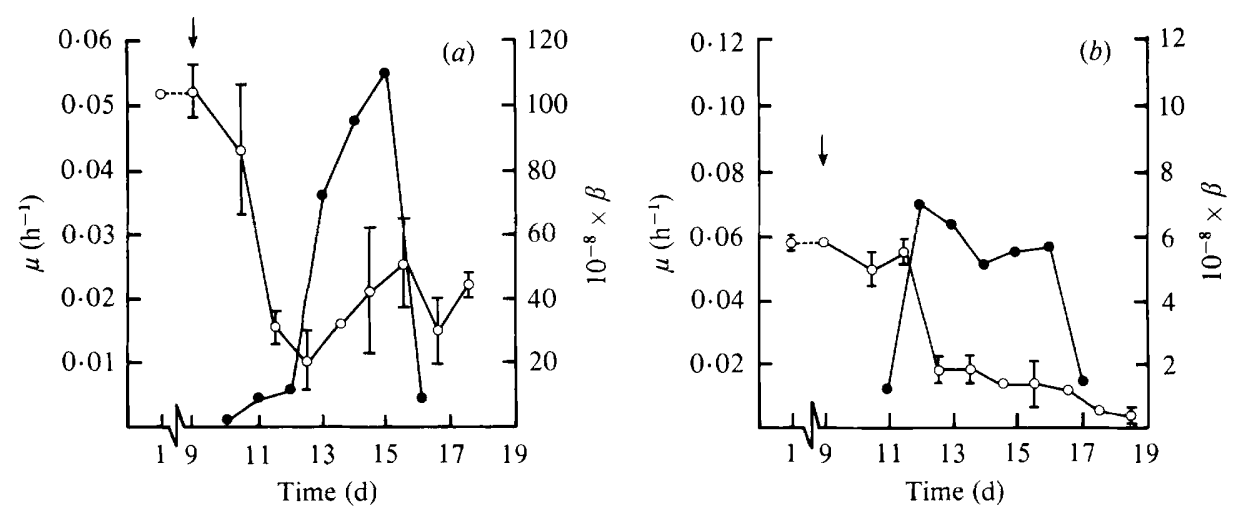

Fig. 5. Effect of shock nitrate limitation on the growth rate, $\mu(O)$ and sporulation index, $\beta(O)$ of $(a)$ $A$. ochraceus [medium $\mathrm{N}$ concentration suddenly reduced (arrow) from 0.214 to $0.0214 \mathrm{~g} \mathrm{l}^{-1}$ ] and $(b)$ $A$. niger [medium $\mathrm{N}$ concentration suddenly reduced (arrow) from 0.21 to $0.021 \mathrm{~g}^{-1}$ ]. $\beta$ represents the number of spores per $\mathrm{g}$ dry wt mycelium. $D, 0 \cdot 1 \mathrm{~h}^{-1}$; temp., $30^{\circ} \mathrm{C}$; medium sucrose concentration, $5 \cdot 0$ $\mathrm{g}^{-1}$. The bars represent the standard errors of three replicates.

several times using $A$. ochraceus, but the organism died when $K_{\mathrm{s}}$ was decreased to $0.4 \mathrm{~g} \mathrm{~h}^{-1}$, and no sporulation resulted.

Maintenance coefficients for starch of $0.0383 \mathrm{~g} \mathrm{~g}^{-1} \mathrm{~h}^{-1}$ for $A$. niger (Fig. $3 b$ ) and $0.123 \mathrm{~g}$ $\mathrm{g}^{-1} \mathrm{~h}^{-1}$ for $A$. ochraceus were calculated.

\section{Nitrogen limitation}

Gradual limitation. Maintaining a carbon supply of $5.0 \mathrm{~g}$ sucrose $\mathrm{l}^{-1}$, at $D=0.2 \mathrm{~h}^{-1}$, the nitrogen content of the medium was reduced stepwise, allowing the fermentation to approximate to a steady state between each stage (during nutrient limitation, steady-state operation is rarely encountered). The results for $A$. niger and $A$. ochraceus are presented in Fig. $4(a, b)$. In both cases there was no sporulation, although growth was very slow, the mould adapting to the change in environment. One particular $A$. niger fermentation was run for $1536 \mathrm{~h}$ with a nitrogen concentration of $0.02 \mathrm{~g} \mathrm{l}^{-1}$ or less with no sign of sporulation. It is suggested that the organism obtains sufficient nitrogen supply for maintenance and growth from the autolysis of dead cells at the low dilution rate. Pannell (1976) also observed this effect. 
(a) A.ochraceus
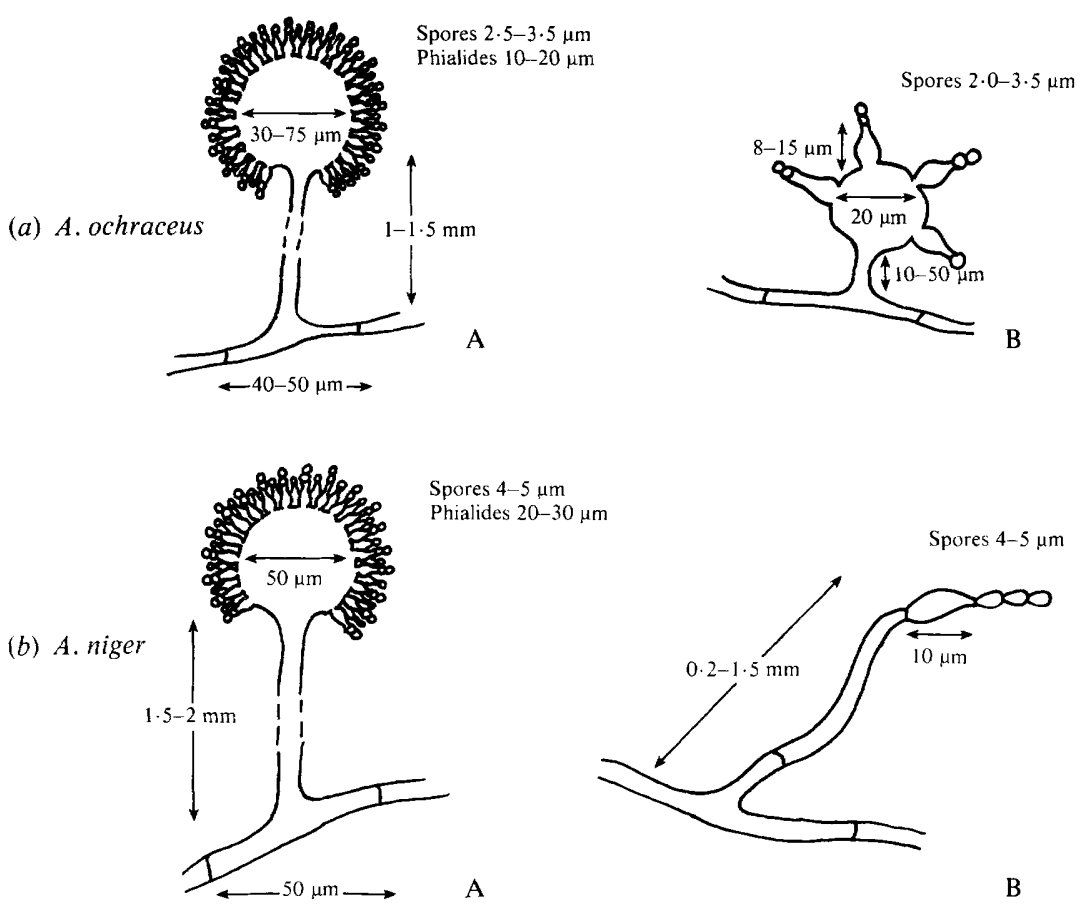

Fig. 6. Semi-diagrammatic representation of submerged sporulation structures of $(a) A$.ochraceus and (b) A. niger. A, sub-aerial form; B, simplified form in continuous culture after imposition of shock nitrogen limitation (see Fig. 5).

Shock limitation. After several days at optimum conditions and at a steady state, the nitrogen supply for $A$. ochraceus was suddenly reduced from 0.214 to $0.0214 \mathrm{~g} \mathrm{l}^{-1}$ (Fig. $5 a$ ). Sporulation began approximately $10 \mathrm{~h}$ after the initiation of nitrogen limitation, when conidiophore initials were seen. After $16 \mathrm{~h}$ vesicles were present, and sporulation was complete after $18 \mathrm{~h}$, upon the production of phialides and spores. Again, sporulation was not synchronous and continued for $7 \mathrm{~d}$, after which time the fermentation was stopped due to infection. Although sub-aerial sporing structures were seen, the majority of structures were unusual, having a much reduced conidiophore bearing an apparently normal vesicle which held few (sometimes only two) phialides (Fig. $6 a$ ). The spore size was normal $(2 \cdot 0-3.5 \mu \mathrm{m}$ diam.); no spore chains were seen. The sporulation index values from one experiment (Fig. 5 a) show that spore production reached a peak after $6 \cdot \mathrm{d}$ of nitrogen limitation, and then declined rapidly until, after $9 \mathrm{~d}$, there were no spores visible, when the fermentation was stopped. An important observation during this fermentation was that of 'microcycle' conidiation. The incidence of the structures associated with this phenomenon was relatively low, but their presence indicates that the environment of the tower was capable of supporting the germination of spores produced in that system, and was also such that almost immediate re-sporulation of the germ-tube was induced. The nutrient interactions here are complex and an immediate explanation of this phenomenon was not apparent.

The experiment of shock nitrate limitation was repeated using $A$. niger, and an optimum steady state was achieved on a full medium supply at $D=0 \cdot 1 \mathrm{~h}^{-1}$. The nitrate supply was then decreased from 0.21 to $0.021 \mathrm{~g} \mathrm{~N}^{-1}$ (Fig. $5 b$ ). As with the carbon limitation experiments, $\mu$ decreased very shortly after nutrient limitation, due to washout of the organism (at a particular dilution rate and nutrient concentration, the fermenter is only capable of supporting a limited fermenter population). Sporulation occurred approximately $12 \mathrm{~h}$ after the onset of limitation and continued for $8 \mathrm{~d}$, when sporulation ceased and the 
fermentation was terminated. Spore production was not as heavy as with $A$. ochraceus (sporulation index, Fig. $5 b$ ) but was found to be equally easily repeated. There were a variety of sporing structures produced, ranging from complex (sub-aerial type) to much simplified structures (those produced in the shortest time of $12 \mathrm{~h}$ ) of single large phialides borne on hyphal tips (Fig. $6 b$ ). Sporulation was not synchronous and a complete range of structures were produced together. One should note that $\mu$ never reached zero during sporulation and carbon utilization did not drop appreciably at any time during nutrient limitation. The fermentation parameters exhibited damped oscillations after the shock stimulus, during which time sporulation occurred, and later gradually levelled out to an almost steady state, by which time sporulation had ceased.

\section{DIS C USSION}

It was possible with the continuous tower fermenter system to estimate the maintenance level of the carbohydrate supply to the fungi by extrapolating graphs of growth rate $(\mu)$ against specific substrate utilization rate $(q)$ to the point of zero growth. The values of $0.018 \mathrm{~g}$ sucrose $\mathrm{g}^{-1} \mathrm{~h}^{-1}$ and $0.0383 \mathrm{~g}$ starch $\mathrm{g}^{-1} \mathrm{~h}^{-1}$ for $A$. niger calculated from our results are similar to published values for the carbohydrate maintenance requirement of other filamentous fungi (Table 1), but the value of $0.123 \mathrm{~g}$ starch $\mathrm{g}^{-1} \mathrm{~h}^{-1}$ for A. ochraceus is considerably higher than any previously calculated value. This may be due to the slow growth rate of this organism. It was not possible to calculate a maintenance coefficient value for nitrogen, as growth rate and productivity were still positive when utilization had apparently reached zero with no nitrogen supply to the culture. This agrees with the fact that the organism can utilize a carbohydrate source for respiration and growth in the absence of a nitrogen supply, while the reverse is not possible. Thus, growth ceases when sufficient carbohydrate is removed from the supply, but continues when all nitrogen is removed from the medium. At this point the organism is assumed to obtain sufficient nitrogen from autolysis of dead cells. This was most evident in the $A$. niger cultures, which were able to survive for long periods on their own lysis nitrogen products with medium that contained no nitrogen source but had all other nutrients in excess. This condition could not last indefinitely, because only sufficient nitrogen was available for the maintenance of existing cells and not for the production of new cells, i.e. there was no increase in mycelial mass. The existing cells therefore gradually die and are not replaced, although this is a very slow process.

Our results provide evidence that sporulation occurs at substrate levels slightly above the maintenance ration (sucrose $0.102 \mathrm{~g} \mathrm{~g}^{-1} \mathrm{~h}^{-1}$ to $A$. niger, starch $0.093 \mathrm{~g} \mathrm{~g}^{-1} \mathrm{~h}^{-1}$ to $A$. ochraceus and $0.04 \mathrm{~g} \mathrm{~g}^{-1} \mathrm{~h}^{-1}$ to $A$. niger), a phenomenon which was also noted by Righelato et al. (1968) and $\mathrm{Ng}$ et al. (1972).

We agree with Smith et al. (1977) that it is "better to consider that vegetative growth and sporulation are cellular processes competing for limiting metabolic intermediates rather than as mutually exclusive phenomena', because growth continued throughout each sporulative phase. This observation may be distorted because fermenter productivity, and hence growth rate, is influenced not only by the physical and nutritional parameters but also by the organism morphology induced by these restraints. As a consequence of nutrient limitation, the gross mycelial floc morphology alters to a form of type I-II (Cocker, 1980), more easily removed from the fermenter; this results in a gradual washout which lowers the fermenter biomass concentration and falsely increases fermenter output. Growth, as calculated by the increase in mycelial dry weight, is probably due to the formation of sporulation structures and not to hyphal biomass.

The most intriguing aspect of this work was the unusual morphology of the sporulating structures observed. There are conflicting reports on the submerged reproductive structures of filamentous fungi. Carter \& Bull (1969) describe submerged structures of Aspergillus nidulans as identical to sub-aerial structures. Galbraith \& Smith $(1969 a)$ also state that the 
Table 1. Calculated maintenance coefficients of carbohydrate supply for filamentous fungi in continuous culture

$\quad$ Organism
Penicillium chrysogenum
Aspergillus nidulans
Aspergillus nidulans
Aspergillus niger
Aspergillus niger
Aspergillus niger

Organism

Penicillium chrysogenum

Aspergillus nidulans

Aspergillus nidulan

Aspergillus niger

Aspergillus niger

$\begin{array}{lc}\text { Substrate } & \begin{array}{c}\text { Maintenance coefficient, } \\ m\left(\mathrm{~g} \mathrm{~g}^{-1} \mathrm{l}^{-1}\right)\end{array} \\ \text { Glucose } & 0.022 \\ \text { Glucose } & 0.018 \\ \text { Glucose } & 0.029 \\ \text { Citrate } & 0.045 \\ \text { Sucrose } & 0.015 \\ \text { Starch } & 0.04\end{array}$

\author{
Reference \\ Righelato et al. (1968) \\ Carter et al. (1971) \\ Bainbridge et al. (1971) \\ $\mathrm{Ng}$ et al. (1973) \\ Pannell (1976) \\ Spensley (1977)
}

submerged sporulation structures observed were identical to those of static cultures, although lacking conidial chains. Similarity between submerged and sub-aerial structures has also been reported by Righelato et al. (1968), Vezina et al. (1965) and Hadley \& Harrold (1958). Evidence for the reduction of complexity of submerged sporing structures is equally well documented. Anderson \& Smith $(1971 b)$ observed direct production of phialides on tips of germ-tubes of $A$. niger and $\mathrm{Ng}$ et al. (1973) reported considerable reduction of complexity of the conidial apparatus of $A$. niger in chemostat culture. Various 'microcycle' sporulation structures have also been described for A. niger (Anderson \& Smith, $1971 b$ ) and Penicillium urticae (Sekiguchi et al., 1975). Our experiments produced much simplified reproductive structures of both $A$. niger and A. ochraceus. Structures produced in continuous culture under carbon limitation were all similar to the sub-aerial form, and any simplification (e.g. A. niger on starch) was reflected in the decreased number of phialides and spores. The structures produced by $A$. niger and $A$. ochraceus during nitrogen limitation were predominantly much simplified. However, in the nitrogen-limited cultures, a range of reproductive structures, from complex to very simple, were frequently observed along the same hypha. Explanation of the simplification of sporulation morphology is thus complicated; we consider that the exact switch-over point to a sporulative metabolism has not yet been defined. $\mathrm{Ng}$ et al. (1973) suggested that the simplification of morphology is due to a partial switching on of the conidiation mechanism, with the morphological and biochemical events of development that preclude spore formation being by-passed. They also suggested that the residence time of the mycelium in the fermenter may determine the morphology of sporulation, but this seems unlikely on the evidence of our work. Dilution rate, and hence residence time, determined the incidence of sporulation (under nitrogen-limited conditions, a dilution rate of $0.4 \mathrm{~h}^{-1}$ inhibited sporulation, while spores were formed under identical conditions at dilution rates of $0.2 \mathrm{~h}^{-1}$ and $0.1 \mathrm{~h}^{-1}$ ), but exerted no control over the morphology of sporulation. Sporing structures were produced primarily at the edges of a mycelial floc, with the centre of the floc remaining vegetative. This indicated that those hyphae at the edge of the floc which have access to the limited nutrients available use these nutrients to produce spores. The observation of adjacent complex and simplified structures suggests that the morphology produced depends upon the availability of nutrients and oxygen along the hypha within the peripheral zone of the floc. Hence those structures near the hyphal tip, which has greater access to nutrients, would be complex, while further back along the hypha, structures would become increasingly simplified. However, there is as yet no evidence of this.

The induction of the reproductive phase of the organisms is considered analogous to the induction of a non growth-associated secondary metabolite, and as such the production of the desired product (i.e. spores) continues only for a finite period of time. Dawes \& Thornley (1970) reported that the steady-state conditions of spore formation by Bacillus subtilis were not maintained indefinitely, due to the spontaneous appearance of asporogenous mutants, which replaced the sporing organism. This was not the case with either of the fungi we tested, because samples taken after the sporulation phase, and plated out at $30^{\circ} \mathrm{C}$ produced perfect spore mats in 10-12 d. It is a feature of submerged continuous culture of filamentous fungi 
that the capacity for sporulation is gradually lost, but Pannell (1976) considered this to be physiological rather than genetic, although the precise cause is not known. Such loss of sporulative capacity was only noted in our work with any fermentation conducted for 6 months or longer. Pannell (1976) found that sporulative ability was restored in subcultures of low-sporing strains. This was also the case in our experiments, but new fermentations were always started from a new master-culture. The loss of sporulative capacity is considered to be a response to the physicochemical stress and continual growth restraint imposed upon the fungus in this system.

During sporulation, overall growth rate decreases and therefore $x_{\mathrm{F}}$ decreases. As a result, the substrate supply per $\mathrm{g}$ dry wt mycelium increases, thus slowly removing the stimulus of nutrient limitation and ending sporulation. A cycling of nutrient levels in this way may explain the 'microcycle' conidiation observed.

It is proposed to establish a semi-continuous system by cyclic medium supply using one medium to induce conidiation, and a second to increase growth (and $x_{F}$ ) after sporulation has ceased, before imposing new growth restraint. The effects of physical parameters such as $\mathrm{pH}$, temperature, dilution rate, and oxygen and carbon dioxide supply, which are easily controlled in the continuous tower fermenter, will also be investigated. It is already known that $\mathrm{pH}$ exerts a major effect upon mould morphology (Galbraith \& Smith, 1969 b; Stockbridge, 1979).

The effect of nutrient limitation upon sporulation is a complex phenomenon and is closely linked with the influence of the physicochemical environment of the continuous tower fermenter. We consider that continuous sporulation is the result of the summation of two or more elements of the physicochemical environment. However, the work described here indicates that control over sporulation in continuous submerged culture is possible using the continuous tower fermenter system, and leads to previously unobserved morphological forms.

The authors wish to thank the Directors of Dunlop Bioprocesses Ltd for the provision of a grant with which this work was undertaken, and the interest and encouragement of Dr R. German.

This paper is dedicated to Nichola Norma Greenshields.

\section{REFERENCES}

Anderson, J. G. \& SMith, J. E. (1971a). Synchronous initiation and maturation of Aspergillus niger conidiophores in submerged culture. Transactions of the British Mycological Society 56, 9-29.

ANDERSON, J. G. \& SMITH, J. E. $(1971 b)$. The production of conidiophores and conidia by newly germinated conidia of Aspergillus niger (microcycle). Journal of General Microbiology 69 , 185-197.

Bainbridge, B. W., Bull, A. T., Pirt, S. J., Rowley, B. I. \& TrINCI, A. P. J. (1971). Biochemical and structural changes in non-growing, maintained and autolysis cultures of Aspergillus nidulans. Transactions of the British Mycological Society 56, 371-385.

Carter, B. L. A. \& Bull, A. T. (1969). Studies of fungal growth and intermediate carbon metabolism under steady and non-steady state conditions. Biotechnology and Bioengineering 11, 785-804.

CARTer, B. L. A., Bull, A. T., PirT, S. J. \& Rowley, B. I. (1971). Relationship between energy substrate utilization and specific growth rate in Aspergillus nidulans. Journal of Bacteriology 108, 309-313.

Chapman, B., Cooke, G. H. \& Whitehead, R. (1967). Automated analysis: the determination of ammoniacal, nitrous and nitric nitrogen in river waters, sewage effluents and trade effluents. Journal of the Institute of Water Pollution Control No. 2.

Cochrane, V. W. (1958). Physiology of the Fungi. London \& New York: Wiley.

Cocker, R. (1980). Interactions between fermenter and micro-organism: tower fermenter. In Fungal Biotechnology, pp. 111-124. Edited by J. E. Smith, D. R. Berry \& B. Kristiansen. London \& New York: Academic Press.

Cocker R. \& Greenshields, R. N. (1975). Design for laboratory scale tower fermenters. Laboratory Practice 24, 341-343.

Dawes, I. W. \& Thornley, J. H. M. (1970). Sporulation of Bacillus subtilis. Theoretical and experimental studies in continuous culture systems. Journal of General Microbiology 62, 49-66.

Dubois, M., Gilles, K. A., Hamitton, J. K., Rebers, P. A. \& SMITH, F. (1956). Colorimetric method for determination of sugars and related substances. Analytical Chemistry 28, 350-356.

Dulaney, E. L., Stapley, E. O. \& Lavac, C. H. (1955). Hydroxylation of steroids, principally progesterone, by a strain of Aspergillus ochraceus. Mycologia 47, 464-474. 
Galbraith, J. C. \& SmITH, J. E. (1969a). Sporulation of Aspergillus niger in submerged liquid culture. Journal of General Microbiology 59, 31-45.

Galbraith, J. C. \& Smith, J. E. (1969b). Filamentous growth of Aspergillus niger in submerged shake culture. Transactions of the British Mycological Society 52, 237-246.

Greenshields, R. N. \& PANNell, S. D. (1975). U.K. Patent Application No. 53702/74.

Greenshields, R. N. \& Smith, E. L. (1971). Tower fermentation systems and their applications. Chemical Engineer 249, 182-190.

Greenshields, R. N. \& Smith, E. L. (1974). The tubular reactor in fermentation. Process Biochemistry 9, 11-18.

HADLEY, G. \& Harrold, C. E. (1958). The sporulation of Penicillium notatum Westling in submerged liquid culture. 1. The effect of calcium and nutrients on sporulation intensity. Journal of Experimental Botany 9, 408-447.

Haines, W. J. \& Collingworth, D. R. (1953). U.S. Patent No. 2649401.

Hsu, E. J. \& Ordal, Z. J. (1969). Sporulation of Clostridium thermosaccharolyticum under conditions of restricted growth. Journal of Bacteriology 97, 1511-1512.

MARKHAM, R. (1942). A steam distillation apparatus suitable for micro-Kjeldahl analysis. Biochemical Journal 36, 790.

Morton, A. G. (1961). The induction of sporulation in mould fungi. Proceedings of the Royal Society B 153, 548-569.

Morton, A. G., Dickerson, A. G. F. \& England, D. J. F. (1960). Changes in enzyme activity of fungi during nitrogen starvation. Journal of Experimental Botany 11, 116.

NG, A. M. L., Smith, J. E. \& Anderson, J. G. (1972). Changes in carbon catabolic pathways during the synchronous development of Aspergillus niger. Journal of General Microbiology 71, 495-504.

NG, A. M. L., Smith, J. E. \& McIntosh, A. F. (1973). Conidiation of Aspergillus niger in continuous culture. A rchiv für Mikrobiologie 88, 119-126.

PANNEll, S. D. (1976). Studies in continuous tower fermentation. Ph.D. thesis, University of Aston in Birmingham.

Righelato, R. C., Trinci, A. P. J., Pirt, S. J. \& PEAT, A. (1968). The influence of maintenance energy and growth rate on the metabolic activity, morphology and conidiation of Penicillium chrysogenum. Journal of General Microbiology 50, 399-412.

SCHLEG, M. C. \& KNight, S. G. (1962). Hydroxylation of progesterone by conidia from Aspergillus ochraceus. Mycologia 54, 317-319.

SCHULZE, K. L. \& LIPE, R. S. (1964). Relationship between substrate concentration, growth rate and respiration rate of Escherichia coli, in continuous culture. Archiv für Mikrobiologie 48, 1-20.

Sehgal, S. N., Singh, K. \& Vezina, C. (1968). $11 \alpha$ hydroxylation of steroids by spores of Aspergillus ochraceus. Canadian Journal of Microbiology 14, $529-530$.

Sekiguchi, J., Gaucher, G. M. \& Costerton, J. W. (1975). Microcycle conidiation in Penicillium urticae. (iii) An ultrastructural investigation of conidiogenesis. Canadian Journal of Microbiology 21, 2069-2083.

Smith, E. L. \& Greenshields, R. N. (1974). Tower fermentation systems and their application to aerobic processes. Chemical Engineer 281, 28-34.

Smith, J. E., DEANS, S. G., ANDERSON, J. G. \& DAvis, B. (1977). The nature of fungal sporulation. In Biotechnology and Fungal Differentiation, pp. 1741. Edited by J. Meyrath \& J. D. Bu'lock. London: Academic Press.

SPENSLEY, R. (1977). The utilization of low-grade carbohydrates. Ph.D. thesis, University of Aston in Birmingham.

STOCKBrIDGE, P. J. (1979). The treatment of a food process waste material. Ph.D. thesis, University of Aston in Birmingham.

Vezina, C., Singh, K. \& Sehgal, S. N. (1965). Sporulation of filamentous fungi in submerged culture. Mycologia 57, 722-736.

WEISS, B. \& TURIAN, G. (1966). A study of conidiation in Neurospora crassa. Journal of General Microbiology 44, 407-418. 